\title{
Analysis of Inflammatory Mediator Profiles in Sepsis Patients Reveals That Extracellular Histones Are Strongly Elevated in Nonsurvivors
}

\author{
Tanja Eichhorn $\left(\mathbb{D},{ }^{1}\right.$ Ingrid Linsberger, ${ }^{1}$ Lucia Lauková $\left(\mathbb{D},{ }^{2}\right.$ Carla Tripisciano $\left(\mathbb{D},{ }^{1}\right.$ \\ Birgit Fendl $\mathbb{D}^{1},{ }^{1}$ René Weiss $\mathbb{D}^{1}{ }^{1}$ Franz König ${ }^{\mathbb{D}},{ }^{3}$ Gerhard Valicek, ${ }^{4}$ Georg Miestinger, ${ }^{4}$ \\ Christoph Hörmann, ${ }^{4}$ and Viktoria Weber $\mathbb{D D}^{1,2}$ \\ ${ }^{1}$ Christian Doppler Laboratory for Innovative Therapy Approaches in Sepsis, Danube University Krems, Krems, Austria \\ ${ }^{2}$ Department for Biomedical Research, Center for Biomedical Technology, Danube University Krems, Krems, Austria \\ ${ }^{3}$ Institute for Medical Statistics, Center for Medical Statistics, Informatics and Intelligent Systems, Medical University Vienna, \\ Vienna, Austria \\ ${ }^{4}$ University Hospital St. Pölten, Department for Anaesthesiology and Intensive Care, St. Pölten, Austria
}

Correspondence should be addressed to Viktoria Weber; viktoria.weber@donau-uni.ac.at

Received 5 August 2020; Revised 17 December 2020; Accepted 3 March 2021; Published 18 March 2021

Academic Editor: Settimio Rossi

Copyright ( 92021 Tanja Eichhorn et al. This is an open access article distributed under the Creative Commons Attribution License, which permits unrestricted use, distribution, and reproduction in any medium, provided the original work is properly cited.

\begin{abstract}
The timely recognition of sepsis and the prediction of its clinical course are challenging due to the complex molecular mechanisms leading to organ failure and to the heterogeneity of sepsis patients. Treatment strategies relying on a "one-fits-all" approach have failed to reduce mortality, suggesting that therapeutic targets differ between patient subgroups and highlighting the need for accurate analysis of the molecular cascades to assess the highly variable host response. Here, we characterized a panel of 44 inflammatory mediators, including cytokines, chemokines, damage-associated molecular patterns, and coagulation-related factors, as well as markers of endothelial activation in 30 patients suffering from renal failure in the course of sepsis. All patients received continuous veno-venous hemodialysis with either high cut-off filters or with standard filters, and mediators were quantified for all patients at the initiation of dialysis and after $24 \mathrm{~h}$ and $48 \mathrm{~h}$. Mediator concentrations in individual patients ranged widely, demonstrating the heterogeneity of sepsis patients. None of the mediators correlated with SAPS III or TISS scores. The overall in-hospital mortality of the study population was $56.7 \%$ (57.1\% vs. $56.3 \%$ for high cut-off $v$ s. standard filter). The two filter groups differed regarding most of the mediator levels at baseline, prohibiting conclusions regarding the effect of standard filters versus high cut-off filters on mediator depletion. The elevation and correlation of damage-associated molecular patterns and markers of endothelial activation gave evidence of severe tissue damage. In particular, extracellular histones were strongly increased and were almost 30-fold higher in nonsurvivors as compared to survivors, indicating their diagnostic and prognostic potential.
\end{abstract}

\section{Introduction}

The definition of sepsis as life-threatening organ dysfunction caused by a dysregulated host response to infection emphasizes the significance of the nonhomeostatic host response and highlights the need for timely recognition and treatment of sepsis [1,2].

The clinical course of sepsis is highly heterogeneous and is influenced by both pathogen-related factors (type and load of pathogen, virulence, and site of infection) and host-related factors (age, gender, genetic background, comorbidities, and lifestyle) [3-5]. Therapeutic approaches to target individual mediators, such as lipopolysaccharide (LPS) or proinflammatory cytokines, have failed to demonstrate convincing benefit in clinical trials so far [6-9]. Post hoc analysis indicated benefits for certain patient subgroups in a number of studies, but these effects were diluted across the study population due to its pronounced heterogeneity $[10,11]$. 
Sepsis is initiated by the recognition of pathogens via pathogen-associated molecular patterns (PAMPs) on innate immune cells, triggering the release of cytokines and chemokines [12, 13]. Simultaneously, injured host cells secrete damage-associated molecular patterns (DAMPs), including histones, high-mobility group box-1 protein (HMGB-1), and extracellular matrix components, such as heparan sulphate, amplifying the inflammatory response [14]. Activated neutrophils release neutrophil extracellular traps (NETs), chromatin-based structures associated with antimicrobial peptides, histones, myeloperoxidase, and elastase. Excessive NET formation promotes tissue damage and activation of coagulation, as well as endothelial activation and loss of barrier function [15-17]. Furthermore, proinflammatory mediators may induce leukocyte apoptosis, resulting in immune suppression and inability to cope with the primary or with secondary infections $[18,19]$.

To target this imbalance and to support the restoration of immune homeostasis, approaches for extracorporeal immunomodulation including continuous veno-venous hemodialysis (CVVHD) with high cut-off hemofilters have been introduced [20]. In a previous study in 30 patients suffering from renal failure in the course of sepsis, we compared the depletion of IL-6, IL-8, IL-10, and TNF- $\alpha$ with high cut-off versus standard high-flux hemofilters and observed enhanced clearance of IL- 6 and IL- 8 by high cut-off $v s$. standard filters both in vitro and in vivo. This enhanced clearance however did not result in persistently reduced cytokine levels, presumably due to a dynamic release of cytokines over the course of treatment [21]. We further found that plasma samples from individual patients differed considerably with regard to their potential to induce endothelial activation in a cell culture model [22].

Here, we report on inflammatory mediator profiles in the study population, comprising a panel of 44 inflammatory cytokines, chemokines, growth factors, DAMPs, and endothelial activation markers, as well as coagulation-related parameters, which were analyzed both at the initiation of dialysis and over the course of treatment.

\section{Materials and Methods}

2.1. Study Design. Plasma samples from sepsis patients were obtained within a single-center, randomized, controlled clinical study with the primary aim of comparing the depletion of IL-6, IL-8, IL-10, and TNF- $\alpha$ during CVVHD using the high cut-off filter Ultraflux EMiC2 and the standard filter Ultraflux AV1000S, both from Fresenius Medical Care (Bad Homburg, Germany). Both EMiC2 and AV1000S are polysulfone-based filters with a surface area of $1.8 \mathrm{~m}^{2}$ and an approximate molecular weight cut-off of 40 and $30 \mathrm{kDa}$, respectively. The study was approved by the Ethics Committee of the University Clinic St. Pölten, Austria (GS4-EK-3/082-2012), and was performed in accordance with the Declaration of Helsinki. Based on in vitro data on the clearance of IL- 6 with the high cutoff filter $v s$. the standard filter $(4.7 \pm 0.2 v s .0 .8 \pm 0.4 \mathrm{ml} /$ $\mathrm{min})$ and on literature data showing average IL-6 levels of $360 \pm 116 \mathrm{pg} / \mathrm{ml}$ in sepsis patients, a sample size of 15 patients per group was calculated to achieve a power of $80 \% \quad(\alpha=0.05)$, assuming a standardized difference of Cohen's $d=0.90$ between the two treatment groups. The results regarding the primary study aim have been published elsewhere [21]. Here, we characterized the plasma concentrations of 44 inflammatory mediators in the study population over the course of treatment, as detailed below.

2.2. Inclusion Criteria. Patients suffering from acute renal failure in the course of sepsis were included in this study and recruited from November 2013 to October 2015. Acute renal failure was diagnosed according to RIFLE criteria [23]. The diagnosis of sepsis was established on the basis of a proven or suspected infection and the presence of at least two of the following criteria: (i) temperature $>$ $38^{\circ} \mathrm{C}$ or $<36^{\circ} \mathrm{C}$; (ii) heart rate $>90$ beats per min; (iii) respiratory rate $>20$ breaths per min or partial pressure of carbon dioxide in arterial blood $\left(\mathrm{PaCO}_{2}\right)<32 \mathrm{mmHg} ; \quad$ and (iv) white blood cell count $>12 \times 10^{9} / 1,<4 \times 10^{9} / 1$, or $>10 \%$ band forms [24]. Patients younger than 18 years, pregnant patients, and patients with a contraindication for continuous hemodialysis were excluded. Thirty patients were included and randomized either to the high cut-off (EMiC2) group $(n=14)$ or to the standard (AV1000S) filter group $(n=16)$ [21].

2.3. Treatment and Sample Collection. In both groups, CVVHD was performed for $48 \mathrm{~h}$ at a blood flow of $200 \mathrm{ml} / \mathrm{min}$, and citrate was used as an anticoagulant (CiCa protocol, Fresenius Medical Care). At admission, SAPS III (Simplified Acute Physiology Score) and TISS (Therapeutic Intervention Scoring System) scores, leukocyte counts, comorbidities, and the sites of infection were recorded. Blood samples were drawn at the onset of the study $(0 \mathrm{~h})$ and after $24 \mathrm{~h}$ and $48 \mathrm{~h}$ into vacuette tubes containing citrate as the anticoagulant (Greiner Bio-One, Kremsmünster, Austria). All samples were immediately centrifuged (2,000 g, $15 \mathrm{~min}$, $4^{\circ} \mathrm{C}$ ), and the resulting plasma samples were stored at $-80^{\circ} \mathrm{C}$ until further analysis.

2.4. Quantification of Inflammatory Cytokines, Chemokines, and Growth Factors. The Bio-Plex Pro ${ }^{\mathrm{TM}}$ human cytokine 27-plex bead array (Bio-Rad, Vienna, Austria) was used to quantify interleukin- (IL-) $1 \beta$, IL-1 receptor antagonist (IL-1ra), IL-2, IL-4, IL-5, IL-6, IL-7, IL-8, IL-9, IL-10, IL12p70, IL-13, IL-15, IL-17A, interferon-gamma (IFN- $\gamma$ ), tumour necrosis factor-alpha (TNF- $\alpha$ ), monocyte chemotactic protein-1 (MCP-1), macrophage inflammatory protein-1 alpha and beta (MIP-1 $\alpha$, MIP-1 $\beta$ ), regulated on activation, normal T-cell expressed and secreted (RANTES), eosinophil chemotactic protein (eotaxin), interferon-inducible protein 10 (IP-10), granulocyte colony-stimulating factor (G-CSF), granulocytemacrophage colony-stimulating factor (GM-CSF), basic fibroblast growth factor (bFGF), platelet-derived growth factor (PDGF), and vascular endothelial growth factor (VEGF). Plasma samples were diluted to $1: 4$ with sample diluent and analyzed according to the instructions of the manufacturer. Plasma concentrations of C-reactive protein 
TABLe 1: Clinical characteristics of study patients at baseline.

\begin{tabular}{lc}
\hline Characteristics & All patients $(n=30)$ \\
\hline Age (years) & $62.3 \pm 18.3(26-89)$ \\
Gender, male & $19(63 \%)$ \\
SAPS III & $68.4 \pm 12.5(45-107)$ \\
TISS & $39.5 \pm 7.1(26-57)$ \\
Leukocyte count $\left(\times 10^{3} / \mu \mathrm{l}\right)$ & $15.0 \pm 8.6(2-35)$ \\
Comorbidities, number $(\%$ of total) & \\
Cardiovascular & $18(60 \%)$ \\
Pulmonary & $7(23 \%)$ \\
Hepatitis/pancreatitis & $1(3 \%)$ \\
Neurological & $9(30 \%)$ \\
Renal & $5(17 \%)$ \\
Diabetes & $9(30 \%)$ \\
Primary site of infection, number (\% of total) & \\
Lung & $1(3 \%)$ \\
Abdomen & $10(33 \%)$ \\
Blood & $7(23 \%)$ \\
Urinary tract & $3(10 \%)$ \\
Other & $7(23 \%)$ \\
Unknown & $2(7 \%)$ \\
\hline
\end{tabular}

Data are represented as mean \pm standard deviation (range) or $n$ (\%). SAPS III: Simplified Acute Physiology Score III; TISS: Therapeutic Intervention Scoring System.

(CRP), soluble CD14 (sCD14), growth arrest-specific gene 6 (Gas6), and soluble suppression of tumorigenicity 2 (sST2) were quantified by the enzyme-linked immunosorbent assay (ELISA; R\&D Systems Minneapolis, MN). LPS-binding protein (LBP) was measured by ELISA (Biometec, Greifswald, Germany).

The hybcell antibody microarray (CubeDX, St. Valentin, Austria) was used to quantify procalcitonin (PCT) and cystatin C. The Bromocresol Green Albumin Assay (SigmaAldrich, St. Louis, MO) was used to quantify albumin.

2.5. Quantification of Endothelial Activation Markers. Plasma concentrations of the endothelial-associated proteoglycan endothelial cell-specific molecule-1 (ESM-1, endocan) were determined by ELISA (Lunginnov, Lille, France). Angiopoietin-1 (Ang-1) and Ang-2 were quantified by ELISA (R\&D Systems).

2.6. Quantification of DAMPs. Extracellular DNA (ecDNA) was isolated from $100 \mu \mathrm{l}$ of plasma from septic patients using the QIAamp DNA Mini Kit (Qiagen, Hilden, Germany) according to the recommended protocol, and total ecDNA was quantified with a Qubit fluorometer and dsDNA HS Assay Kit (Thermo Fisher Scientific, Waltham, MA). Extracellular histones were determined as components of nucleosomes using the cell death detection ELISA (Roche, Mannheim, Germany), wherein a monoclonal anti-histone antibody is used as a catching antibody in combination with a monoclonal anti-DNA antibody conjugate for detection. A
TABLE 2: Biomarker profiles in sepsis patients at baseline $(n=30)$.

\begin{tabular}{|c|c|c|c|}
\hline \multicolumn{2}{|l|}{ Parameter } & Median & IQR $\left(25^{\text {th }}-75^{\text {th }}\right.$ quartile $)$ \\
\hline \multicolumn{4}{|c|}{ Inflammatory mediators } \\
\hline $\mathrm{IL}-1 \beta$ & $(\mathrm{pg} / \mathrm{ml})$ & 6.82 & $4.37-14.55$ \\
\hline IL-1ra & $(\mathrm{pg} / \mathrm{ml})$ & 670.66 & 266.44-1,231.08 \\
\hline IL-2 & $(\mathrm{pg} / \mathrm{ml})$ & 7.62 & $1.12-32.42$ \\
\hline IL-4 & $(\mathrm{pg} / \mathrm{ml})$ & 6.36 & $4.82-10.11$ \\
\hline IL-5 & $(\mathrm{pg} / \mathrm{ml})$ & 19.94 & $15.94-35.56$ \\
\hline IL-6 & $(\mathrm{pg} / \mathrm{ml})$ & 277.02 & $103.65-1,091.49$ \\
\hline IL-7 & $(\mathrm{pg} / \mathrm{ml})$ & 8.14 & $4.64-22.54$ \\
\hline IL-8 & $(\mathrm{pg} / \mathrm{ml})$ & 104.56 & $53.26-198.48$ \\
\hline IL-9 & $(\mathrm{pg} / \mathrm{ml})$ & 15.76 & $8.62-34.04$ \\
\hline IL-10 & $(\mathrm{pg} / \mathrm{ml})$ & 28.48 & $10.59-65.04$ \\
\hline IL-12 & $(\mathrm{pg} / \mathrm{ml})$ & 19.54 & $8.71-45.81$ \\
\hline IL-13 & $(\mathrm{pg} / \mathrm{ml})$ & 6.68 & $0.84-11.68$ \\
\hline IL-15 & $(\mathrm{pg} / \mathrm{ml})$ & 14.30 & $1.36-57.00$ \\
\hline IL-17 & $(\mathrm{pg} / \mathrm{ml})$ & 49.22 & $19.65-86.74$ \\
\hline IFN- $\gamma$ & $(\mathrm{pg} / \mathrm{ml})$ & 173.40 & $112.79-295.45$ \\
\hline TNF- $\alpha$ & $(\mathrm{pg} / \mathrm{ml})$ & 84.56 & $44.98-152.19$ \\
\hline CRP & $(\mathrm{mg} / \mathrm{l})$ & 208.15 & $164.26-283.67$ \\
\hline PCT & (ng/ml) & 3.00 & $0.78-4.36$ \\
\hline LBP & $(\mu \mathrm{g} / \mathrm{ml})$ & 114.93 & $77.47-172.14$ \\
\hline sCD14 & $(\mathrm{ng} / \mathrm{ml})$ & $3,159.00$ & $2,728.00-3,721.00$ \\
\hline sST2 & $(\mathrm{ng} / \mathrm{ml})$ & 372.36 & $173.64-589.74$ \\
\hline Gas6 & $(\mathrm{ng} / \mathrm{ml})$ & 43.15 & $34.03-55.44$ \\
\hline \multicolumn{4}{|l|}{ Chemokines } \\
\hline MCP-1 & $(\mathrm{pg} / \mathrm{ml})$ & 125.72 & 49.97-385.93 \\
\hline MIP- $1 \alpha$ & $(\mathrm{pg} / \mathrm{ml})$ & 8.48 & $5.72-12.92$ \\
\hline MIP-1 $\beta$ & $(\mathrm{pg} / \mathrm{ml})$ & 120.94 & $96.09-200.34$ \\
\hline RANTES & $(\mathrm{pg} / \mathrm{ml})$ & $2,014.36$ & $1,088.59-3,285.85$ \\
\hline Eotaxin & $(\mathrm{pg} / \mathrm{ml})$ & 95.78 & $59.67-116.16$ \\
\hline IP-10 & $(\mathrm{pg} / \mathrm{ml})$ & $1,375.94$ & $822.83-2,734.51$ \\
\hline \multicolumn{4}{|c|}{ Growth factors } \\
\hline G-CSF & $(\mathrm{pg} / \mathrm{ml})$ & 161.60 & $70.82-637.97$ \\
\hline GM-CSF & $(\mathrm{pg} / \mathrm{ml})$ & 54.32 & $13.46-109.47$ \\
\hline FGF & $(\mathrm{pg} / \mathrm{ml})$ & 79.94 & $56.00-116.24$ \\
\hline PDGF & $(\mathrm{pg} / \mathrm{ml})$ & 118.70 & $68.22-218.79$ \\
\hline VEGF & $(\mathrm{pg} / \mathrm{ml})$ & 25.98 & $10.39-60.54$ \\
\hline \multicolumn{4}{|c|}{$\begin{array}{l}\text { Endothelial activation } \\
\text { markers }\end{array}$} \\
\hline ESM-1 & $(\mathrm{ng} / \mathrm{ml})$ & 6.00 & $3.86-12.95$ \\
\hline Ang-1 & $(\mathrm{ng} / \mathrm{ml})$ & 0.59 & $0.43-1.22$ \\
\hline Ang-2 & $(\mathrm{ng} / \mathrm{ml})$ & 13.85 & $7.85-33.21$ \\
\hline Ang-2/Ang & & 22.99 & $8.96-61.99$ \\
\hline \multicolumn{4}{|c|}{ Damage-associated molecular patterns } \\
\hline $\mathrm{ecDNA}^{\mathrm{a}}$ & $(\mathrm{ng} / \mathrm{ml})$ & 545.02 & 276.11-1,194.48 \\
\hline Histones $^{\mathrm{a}}$ & $(\mathrm{mg} / \mathrm{ml})$ & 6.60 & $0.45-24.67$ \\
\hline HMGB-1 ${ }^{\text {b }}$ & $(\mathrm{ng} / \mathrm{ml})$ & 3.70 & $2.6-6.91$ \\
\hline \multicolumn{4}{|c|}{ Coagulation-related parameters } \\
\hline $\mathrm{TF}$ & $(\mathrm{pg} / \mathrm{ml})$ & 66.98 & 50.64-91.59 \\
\hline TF activity & $(\mathrm{pM})$ & 38.13 & 24.57-55.79 \\
\hline
\end{tabular}


TABLE 2: Continued.

\begin{tabular}{lccc}
\hline Parameter & & Median & IQR $\left(25^{\text {th }}-75^{\text {th }}\right.$ quartile $)$ \\
\hline Others & & & \\
Cystatin C & $(\mu \mathrm{g} / \mathrm{ml})$ & 3.75 & $2.92-4.05$ \\
Albumin & $(\mathrm{g} / \mathrm{dl})$ & 3.38 & $2.83-3.81$ \\
\hline
\end{tabular}

Data are represented as median and interquartile range (IQR, $25^{\text {th }}-75^{\text {th }}$ quartile). ${ }^{\mathrm{a}} n=29 ;{ }^{\mathrm{b}} n=27$.

mixture of histones $\mathrm{H} 1, \mathrm{H} 2 \mathrm{~A}, \mathrm{H} 2 \mathrm{~B}, \mathrm{H} 3$, and $\mathrm{H} 4$ from the calf thymus (Roche) was used as a standard. High-mobility group box-1 protein (HMGB-1) was quantified by ELISA (IBL International, Hamburg, Germany).

\subsection{Quantification of Coagulation-Related Parameters.} Plasma concentrations of tissue factor (TF) were measured by ELISA (R\&D Systems). Tissue factor activity was analyzed with the Actichrome TF assay (Sekisui Diagnostics, Stamford, CT).

2.8. Statistical Analysis. Descriptive results of continuous variables are expressed as median and $25^{\text {th }}$ to $75^{\text {th }}$ quartiles, except for clinical characteristics at baseline which are indicated as mean \pm standard deviation (range). For calculation, values of mediators that remained below the detection limit of a given test were set equal to the lower detection limit. Differences in inflammatory mediator concentrations among survivors and nonsurvivors at baseline were analyzed by the nonparametric Mann-Whitney test. The same test was used to assess statistical differences in inflammatory mediator concentrations at baseline and after $48 \mathrm{~h}$ between the filter groups. Repeated measures two-way ANOVA followed by Bonferroni's multiple comparison test was performed to assess the filter (EMiC2 vs. AV1000S) and time effect (0 vs. $24 v s .48 \mathrm{~h}$ ). This analysis could not be performed for ecDNA, histone, sST2, TF, and TF activity due to the lack of data at $24 \mathrm{~h}$ and $48 \mathrm{~h}$ for these parameters. For correlation analysis, all parameters were $\log _{10}$-transformed to obtain a proportionally constant variation. Correlations among various biomarkers were tested for significance using the nonparametric Spearman correlation test. For all statistical tests, a value of $p<0.05$ was considered to be statistically significant.

\section{Results}

3.1. Patient Characteristics. Thirty patients suffering from sepsis in the course of acute renal failure were included in the study. The demographic and clinical characteristics of the study population at baseline are summarized in Table 1 . The predominant comorbidities of the study population were cardiovascular disease $(60 \%)$, as well as diabetes and neurological disorders $(30 \%$ each). The abdomen represented the primary site of infection (33\%). The overall in-hospital mortality of the study population was $56.7 \%(57.1 \%$ vs. $56.3 \%$ for high cut-off $v$ s. the standard filter, respectively). Age, gender, physiological scores (SAPS III, TISS), and leukocyte counts at admission did not significantly differ between survivors and nonsurvivors (Supplementary Table 1).

3.2. Inflammatory Mediator Concentrations. The baseline median and interquartile range of the 44 inflammatory parameters analyzed in this study are summarized in Table 2. Plasma levels of IL-33 remained undetectable for the majority of patients and were therefore excluded from statistical analysis.

The baseline median and interquartile range of the inflammatory mediators for survivors and nonsurvivors are summarized in Supplementary Table 2. Plasma samples from nonsurvivors showed 28 -fold higher median baseline levels of histones, 7.6-fold higher median levels of IL-2, and 3.1-fold higher median levels of IL-10 as compared to those from survivors. MCP-1, IL-15, and GM-CSF were more than 2-fold elevated in nonsurvivors. Except for histones $(p=0.025)$, however, none of these differences reached statistical significance.

3.3. Correlation of Inflammatory Cytokines, Chemokines, and Growth Factors. A plot of all parameters obtained by Spearman correlation analysis at baseline is shown in Figure 1. The strong correlation of IL- $1 \beta$, IL-1ra, IL-4, IL-6, IL-8, IL10 , IL-15, IFN- $\gamma$, TNF- $\alpha$, MCP-1, G-CSF, and GM-CSF confirmed the presence of a systemic, proinflammatory cytokine and chemokine response in the patient cohort, as detailed in Table 3. In particular, IL- $1 \beta$ correlated with both IFN- $\gamma$ $(r=0.963, p<0.0001)$ and TNF- $\alpha(r=0.936, p<0.0001)$, which also correlated with each other $(r=0.934, p<0.0001$ ). IL-15 and IL-10 were also strongly correlated $(r=0.912$, $p<0.0001)$. We failed to detect a correlation between any of the biomarkers with disease severity, assessed by the SAPS III and TISS scores, except that SAPS III showed a weak negative association with IL-12 $(r=-0.374, p=0.042)$ and FGF $(r=-0.035, p=0.086)$.

\subsection{Damage-Associated Molecular Patterns and Coagulation-} Related Parameters. To investigate the presence of damageassociated molecular patterns released from cells following tissue injury, we quantified extracellular DNA, histones, and HMGB-1, which significantly correlated with each other (Figure 2). In particular, the elevated levels of both extracellular DNA and histones indicated the release of neutrophil extracellular traps (NETs) [15]. Histones also significantly correlated with TF activity, providing further evidence for the presence of an immuno-thrombotic response (Figure 3).

We refrained from a direct quantification of LPS, since plasma components can interfere with the Limulus amoebocyte lysate assay. The elevated levels of LPS-binding protein (LBP) and sCD14, which both act as cofactors for the binding of LPS by toll-like receptors, however, provided strong evidence for the presence of LPS in the plasma samples. LBP significantly correlated with sCD14 and with the acute-phase protein CRP (Figure 3).

3.5. Markers of Endothelial Activation. To assess endothelial activation and alterations in vascular integrity, we quantified the vasoactive factors angiopoietin-1 (Ang-1) and 


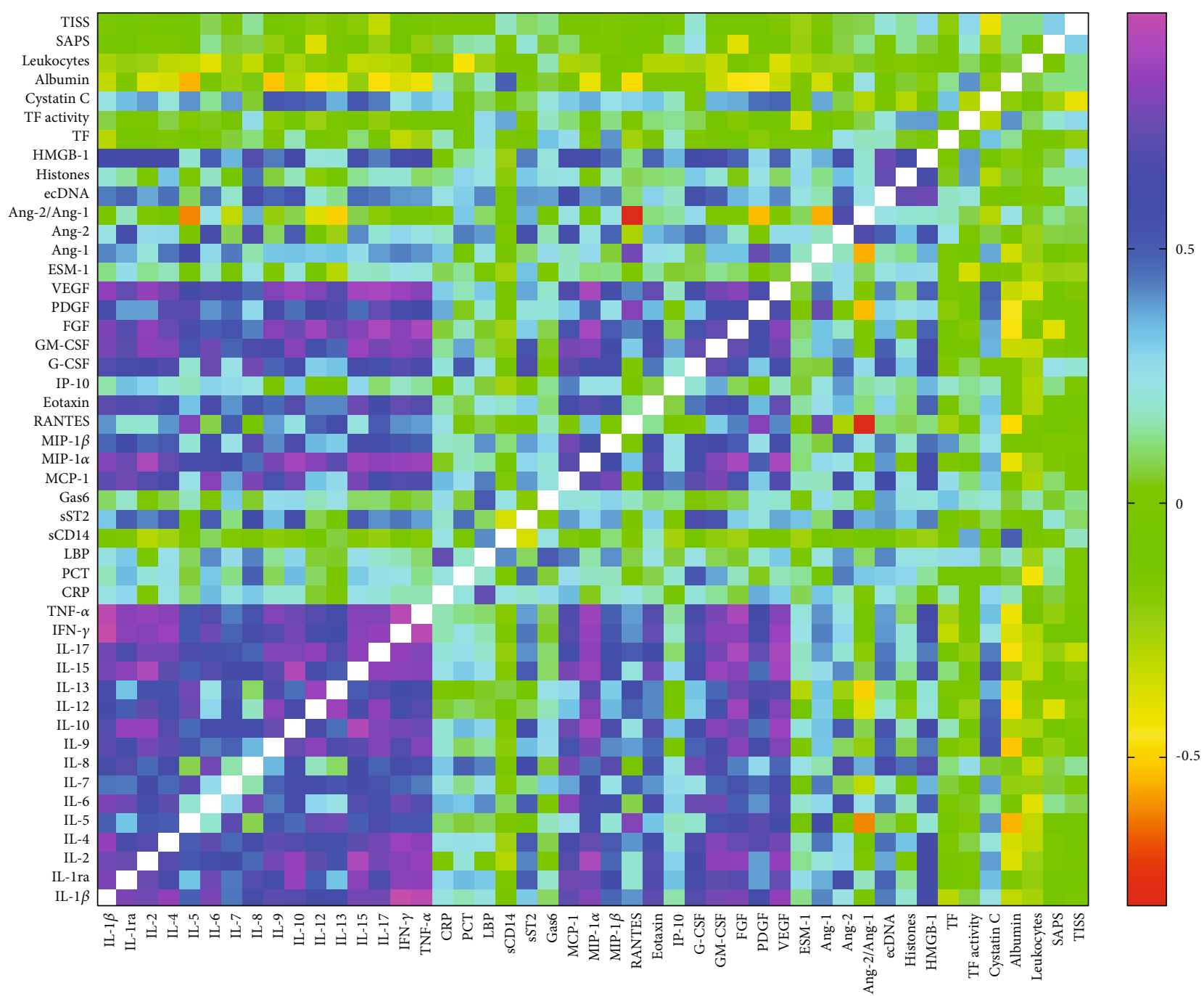

FIgURE 1: Correlation plot of all parameters determined in this study at baseline $(0 \mathrm{~h})$. The plot is based on the Spearman correlation between each pair of biomolecule. On the right, the Spearman correlation coefficient is indicated by the color gradient.

TABLE 3: Correlation analysis of inflammatory cytokines, chemokines, and growth factors $(n=30)$.

\begin{tabular}{|c|c|c|c|c|c|c|c|c|c|c|c|c|}
\hline & IL- $1 \beta$ & IL-1ra & IL-4 & IL-6 & IL-8 & IL-10 & IL-15 & IFN- $\gamma$ & TNF- $\alpha$ & MCP-1 & G-CSF & GM-CSF \\
\hline IL- $1 \beta$ & & 0.787 & 0.835 & 0.788 & 0.581 & 0.692 & 0.771 & 0.963 & 0.936 & 0.719 & 0.687 & 0.775 \\
\hline IL-1 ra & & & 0.660 & 0.757 & 0.689 & 0.844 & 0.820 & 0.818 & 0.825 & 0.759 & 0.641 & 0.714 \\
\hline IL-4 & & & & 0.723 & 0.630 & 0.696 & 0.721 & 0.852 & 0.824 & 0.652 & 0.682 & 0.802 \\
\hline IL-6 & & & & & 0.770 & 0.626 & 0.686 & 0.755 & 0.686 & 0.806 & 0.747 & 0.753 \\
\hline IL-8 & & & & & & 0.591 & 0.607 & 0.581 & 0.539 & 0.782 & 0.762 & 0.666 \\
\hline IL-10 & & & & & & & 0.912 & 0.771 & 0.756 & 0.750 & 0.575 & 0.805 \\
\hline IL-15 & & & & & & & & 0.817 & 0.807 & 0.780 & 0.650 & 0.849 \\
\hline IFN- $\gamma$ & & & & & & & & & 0.934 & 0.687 & 0.699 & 0.813 \\
\hline TNF- $\alpha$ & & & & & & & & & & 0.677 & 0.652 & 0.783 \\
\hline MCP-1 & & & & & & & & & & & 0.715 & 0.784 \\
\hline G-CSF & & & & & & & & & & & & 0.728 \\
\hline GM-CSF & & & & & & & & & & & & \\
\hline
\end{tabular}




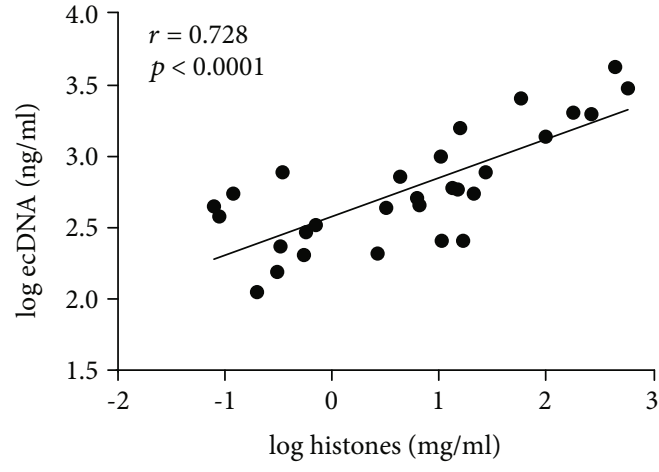

(a)

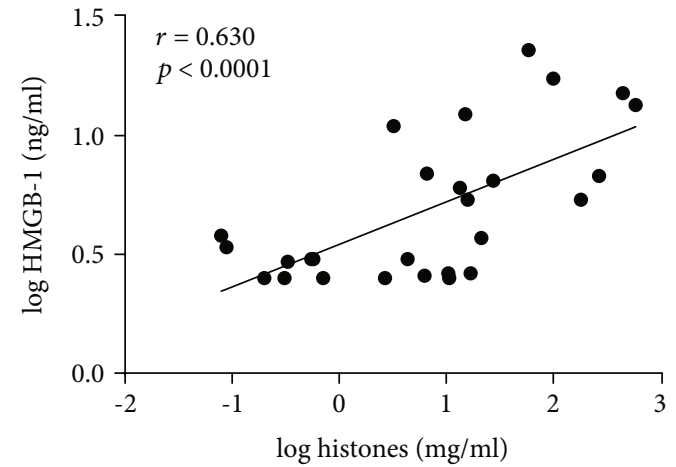

(b)

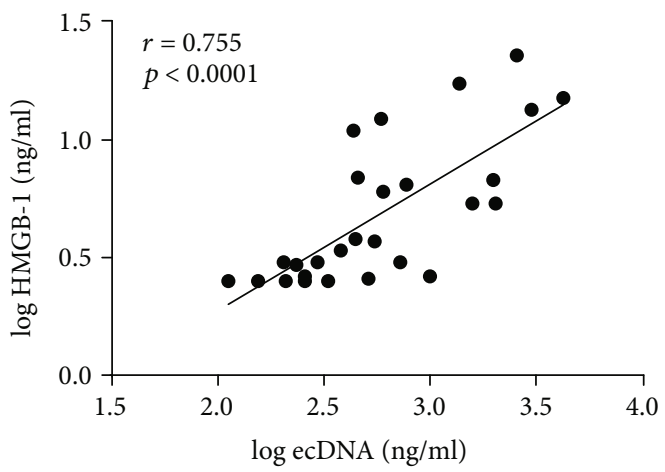

(c)

FIgURE 2: Correlation analysis of damage-associated molecular patterns in septic plasma samples. (a) Histones vs. extracellular DNA (ecDNA), (b) histones $v s$. high-mobility group box-1 protein (HMGB-1), (c) ecDNA vs. HMGB-1. The Spearman correlation test was used to calculate linear relationship between variables at baseline $(0 \mathrm{~h})$. Histones $(n=29)$, ecDNA $(n=29)$, and HMGB-1 $(n=27)$.

Ang-2 as well as endothelial cell-specific molecule-1 (ESM1 , endocan), a proteoglycan mainly expressed by lung endothelial cells, whose secretion into the bloodstream is upregulated by proinflammatory cytokines and LPS [25]. ESM-1 levels were elevated as compared to reference values (Table 2) but did not correlate with any of the inflammatory parameters (Figure 1) [26, 27]. Both Ang-2 levels and the ratio of Ang-2/Ang-1 were substantially increased in our patient cohort, indicating increased vascular permeability. The Ang-2/Ang-1 ratio of 22 was very high as compared to previously published studies, which reported Ang-2/Ang- 1 ratios of 5 for septic shock patients [28-30]. Moreover, we have found moderate positive correlations for Ang-2 and HMGB-1 $(r=0.551, p=0.003)$. Extracellular DNA correlated with Ang-2 $(r=0.491, p=$ $0.007)$ and VEGF $(r=0.419, p=0.024)$. VEGF also showed a positive correlation with HMGB-1 $(r=0.484, p$ $=0.011$ ).

3.6. Depletion of Inflammatory Mediators by High Cut-Off vs. Standard Dialysis. The clinical characteristics of sepsis patients randomized to the treatment groups EMiC2 and AV1000S at baseline are shown in Table 4. Inflammatory mediator profiles in sepsis patients at baseline and after $48 \mathrm{~h}$ for EMiC2 and AV1000S are summarized in Table 5. Except for Gas6, Ang-2, TF, and TF activity, the baseline levels of inflammatory parameters were higher for patients randomized to the AV1000S group than to the EMiC2 group. This difference reached significance for IL-1 $\beta$, IL-1ra, IL-6, IL-8, IL-15, IL-17, GM-CSF, PDGF, VEGF, and cystatin C (Table 5).

Treatment with AV1000S was associated with a significant decrease in IL- $1 \beta$, IL-1ra, IL-2, IL-15, IL-17, TNF- $\alpha$, eotaxin, GM-CSF, and VEGF over time ( $0 \mathrm{~h} v s .24 \mathrm{~h}$ and $0 \mathrm{~h}$ $v s .48 \mathrm{~h}$ ). Additionally, a significant reduction at $48 \mathrm{~h}$ was found for IL-4, IL-6, IFN- $\gamma$, PCT, MCP-1, MIP- $1 \alpha$, RANTES, IP-10, FGF, PDGF, and Ang-2. None of the inflammatory parameters decreased significantly over time for EMiC2, except for PCT (Figure 4). Despite the increased cut-off of the EMiC2 filter, albumin concentrations remained unaffected over time (data not shown).

\section{Discussion}

The characterization of inflammatory mediator profiles and their dynamic alterations can provide a basis for the timely prediction of the clinical course of sepsis and for the improved management of sepsis patients [5, 31, 32].

Here, we characterized a panel of 44 parameters in septic plasma samples, including cytokines, chemokines, growth factors, damage-associated molecular patterns, endothelial activation markers, and coagulation-related factors to depict the molecular mechanisms underlying sepsis on multiple levels. The study population included 


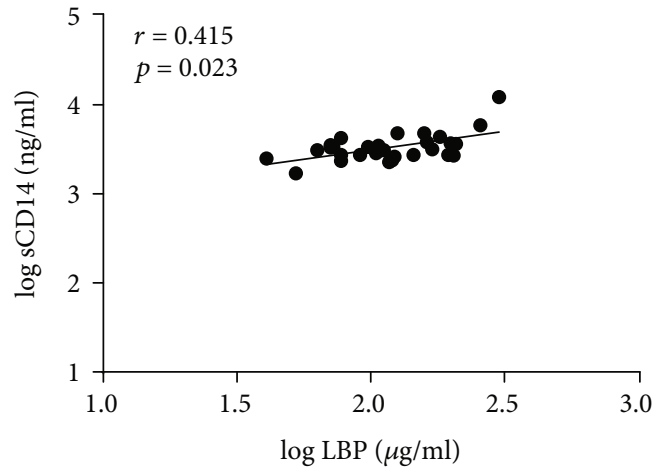

(a)

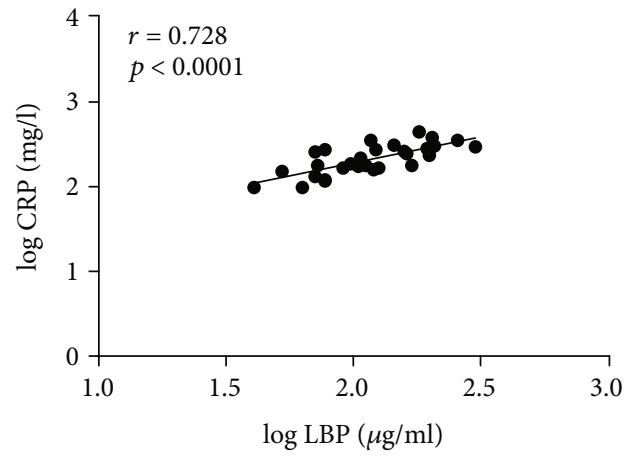

(b)

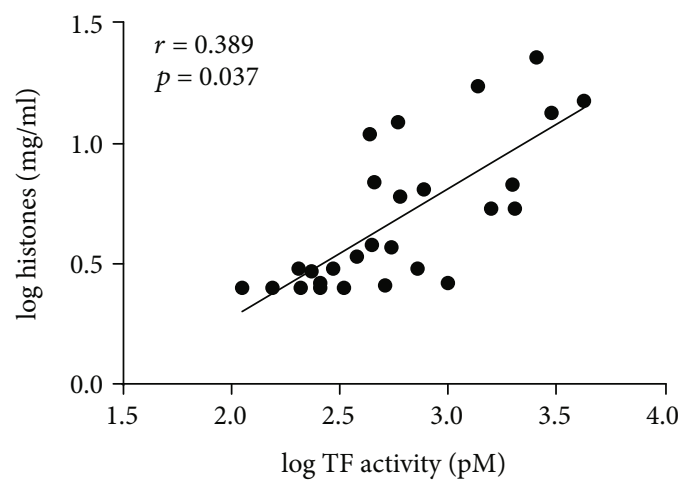

(c)

FIgURE 3: Correlation analysis of inflammatory mediators in septic plasma samples. (a) LBP vs. soluble CD14 (sCD14), (b) lipopolysaccharide-binding protein (LBP) vs. C-reactive protein (CRP), and (c) tissue factor (TF) activity vs. histones. The Spearman correlation test was used to measure the degree of association between variables at baseline $(0 \mathrm{~h} ; n=30 \mathrm{for} \mathrm{LBP}, \mathrm{sCD} 14$, CRP, and TF activity; $n=29$ for histones).

30 patients suffering from acute renal failure in the course of sepsis, who received CVVHD with either high cut-off or standard filters. In line with previous studies, mediator concentrations in the study population at baseline (initiation of dialysis) ranged widely, despite thoroughly defined inclusion criteria [33-36]. The overall mortality was $56.7 \%$, which was high compared to previously published studies [34, 36, 37]. Together with several other parameters, particularly the extremely high ratio of Ang-2/Ang-1 (see below), this indicated the severity of sepsis in our study population.

The strong correlations between IL-1 $\beta$, IL-1ra, IL-4, IL-6, IL- 8 , IL-10, IL-15, IFN- $\gamma$, TNF- $\alpha$, MCP-1, G-CSF, and GMCSF provided evidence for the recruitment of innate immune cells (IL-8, IL-15, MCP-1, G-CSF, and GM-CSF). In line with previous studies $[38,39]$, they further indicated the presence of a proinflammatory immune response (IL- $1 \beta$, IL-6, TNF- $\alpha$, and IFN- $\gamma$ ), with a coexisting anti-inflammatory reaction (IL-1ra, IL-4, and IL-10). In particular, positive correlations between IL-6, IL-8, IL-10, MCP-1, MIP-1 $\beta$, IFN- $\gamma$, and GM-CSF support previous findings [39].

We refrained from the quantification of LPS in plasma samples, since a number of plasma components as well as anticoagulants can interfere with the Limulus amoebocyte lysate assay. However, the elevated plasma concentrations of LBP and sCD14 pointed to the presence of LPS [40], as LBP and sCD14 are released to reduce or inhibit the response to LPS by limiting its interaction with Toll-like receptor- (TLR-) 4 [41, 42]. In addition to its association with sCD14, LBP also correlated with the acute-phase protein CRP. There is accumulating evidence that CRP, beyond its role as a marker for infection, can be actively involved in the propagation of inflammation, particularly when bound to extracellular vesicles released from activated platelets. Moreover, recent data indicate that patients with high CRP levels, together with elevated IL-6 and PCT, are more likely to experience severe complications due to the cytokine storm associated with coronavirus disease (COVID-19) [43].

We included extracellular DNA, histones, and HMGB1 in our analysis, as they represent well-characterized DAMPs whose release is critical in sepsis [15]. All three factors were elevated and strongly correlated with each other, indicating neutrophil activation with NET formation [44-47], which can induce collateral damage to the host and potentiate tissue damage and thrombosis. NETassociated histones, in particular, display direct cytotoxic effects on eukaryotic cells, exert proinflammatory roles upon their release into the extracellular environment, and can contribute to endothelial barrier dysfunction [48-53]. 
TABLE 4: Clinical characteristics of patients randomized to EMiC2 and AV1000S at baseline.

\begin{tabular}{|c|c|c|}
\hline Characteristics & $\operatorname{EMiC} 2(n=14)$ & AV1000S $(n=16)$ \\
\hline Age (years) & $61.7 \pm 16.5(26-81)$ & $62.8 \pm 20.3(26-89)$ \\
\hline Gender, male & $6(43 \%)$ & $13(81 \%)^{*}$ \\
\hline SAPS III & $67.7 \pm 10.3(48-85)$ & $69.0 \pm 14.4(45-107)$ \\
\hline TISS & $40.6 \pm 7.8(30-57)$ & $38.6 \pm 6.4(26-48)$ \\
\hline Leukocyte count $\left(\times 10^{3} / \mu \mathrm{l}\right)$ & $16.2 \pm 7.8(2-34)$ & $14.0 \pm 9.4(2-35)$ \\
\hline Nonsurvivors & $8(57.1 \%)$ & $9(56.3 \%)$ \\
\hline \multicolumn{3}{|c|}{ Comorbidities, number ( $\%$ of total) } \\
\hline Cardiovascular & $8(57 \%)$ & $10(63 \%)$ \\
\hline Pulmonary & $1(7 \%)$ & $6(38 \%)$ \\
\hline Hepatitis/pancreatitis & $1(7 \%)$ & $0(0 \%)$ \\
\hline Neurological & $6(43 \%)$ & $3(19 \%)$ \\
\hline Renal & $1(7 \%)$ & $4(25 \%)$ \\
\hline Diabetes & $3(21 \%)$ & $6(38 \%)$ \\
\hline \multicolumn{3}{|c|}{ Primary site of infection, number (\% of total) } \\
\hline Lung & $1(7 \%)$ & $0(0 \%)$ \\
\hline Abdomen & $5(36 \%)$ & $5(31 \%)$ \\
\hline Blood & $3(21 \%)$ & $4(25 \%)$ \\
\hline Urinary tract & $1(7 \%)$ & $2(13 \%)$ \\
\hline Other & $3(21 \%)$ & $4(25 \%)$ \\
\hline Unknown & $1(7 \%)$ & $1(6 \%)$ \\
\hline
\end{tabular}

Data are represented as mean \pm standard deviation (range) or $n$ (\%). SAPS III: Simplified Acute Physiology Score III; TISS: Therapeutic Intervention Scoring System. ${ }^{*} p=0.030$.

They can trigger a procoagulant phenotype in endothelial cells and stimulate TF expression in a dose-dependent manner [54, 55], as also evidenced by the correlation of histone levels and TF activity in our study population. Our finding that nonsurvivors showed almost 30 -fold higher baseline histone levels than survivors confirmed the significant contribution of histones to cellular injury and multiple organ failure and their potential predictive value for the clinical course of sepsis [56-58].

Next to immunothrombosis, microvascular endothelial dysfunction is a fundamental mechanism in sepsis. Considering this, our analysis included ESM-1, Ang-1, Ang-2, and VEGF as markers of altered endothelial function. ESM-1, a proteoglycan mainly expressed by lung and kidney endothelial cells, is released in response to proinflammatory cytokines $[25,59,60]$. It can block the interaction of monocytes with activated endothelial cells by impeding the binding of the monocytic integrin LFA-1 to endothelial ICAM-1 [61]. Accordingly, we have previously shown that septic plasma samples containing high ESM-1 levels failed to induce monocytic cell adhesion to endothelial cells in vitro [22].

Angiopoietins are essential for vasculogenesis and vascular stability and have been implicated in endothelial dysfunction in sepsis. Ang-1 promotes stabilization and maturation of new blood vessels, whereas Ang-2 can either promote VEGF-induced angiogenesis or destabilize blood vessels in a context-dependent fashion. Increased Ang2/Ang-1 ratios have been described in sepsis and have been associated with disease severity and poor outcome $[29,62]$, as confirmed by the high mortality and the extraordinarily high Ang-2/Ang-1 ratio in our study population.

Patients enrolled in this study received CVVHD with high cut-off filters or with standard filters [21]. After randomization, baseline levels of most inflammatory mediators were higher for the standard filter group vs. the high cut-off filter group, and this difference was statistically significant for a number of factors. Clearly, these different baseline mediator levels are linked to the relatively small sample size of our study and limit conclusions with regard to differences in mediator depletion in the two filter groups. As a further limitation, the panel of parameters evaluated in this study cannot be immediately used for bedside monitoring, but our findings may contribute to the identification of smaller mediator panels to support early diagnosis of sepsis.

In conclusion, the analysis of a panel of inflammationrelated parameters, including cytokines, chemokines, damage-associated molecular patterns, procoagulant factors, and markers of endothelial activation, highlights the high level of heterogeneity in sepsis. The finding that extracellular histones were significantly elevated in nonsurvivors as compared to survivors emphasizes the diagnostic and prognostic potential of circulating histones and nucleosomes. Sepsis patients may benefit from antihistone agents, such as nonanticoagulant heparin or hemoperfusion devices containing beads functionalized with heparin 
TABLE 5: Biomarker profiles in sepsis patients at baseline and after $48 \mathrm{~h}$ for EMiC2 and AV1000S.

\begin{tabular}{|c|c|c|c|c|c|}
\hline \multirow{2}{*}{ Parameter } & & \multicolumn{2}{|c|}{$0 \mathrm{~h}$} & \multicolumn{2}{|c|}{$48 \mathrm{~h}$} \\
\hline & & $\operatorname{EMiC} 2(n=14)$ & AV1000S $(n=16)$ & $\operatorname{EMiC} 2(n=12)$ & AV1000S $(n=10)$ \\
\hline \multicolumn{6}{|c|}{ Inflammatory mediators } \\
\hline IL- $1 \beta$ & $(\mathrm{pg} / \mathrm{ml})$ & $5.92(1.66-9.21)^{*}$ & $8.80(5.60-21.21)$ & $4.12(81.15-5.64)$ & $4.12(2.05-8.43)$ \\
\hline IL-1ra & $(\mathrm{pg} / \mathrm{ml})$ & $301.44(112.64-1,082.40)^{*}$ & $962.12(422.33-2,706.33)$ & $259.44(168.56-383.78)$ & $294.44(142.33-533.06)$ \\
\hline IL-2 & $(\mathrm{pg} / \mathrm{ml})$ & $1.12(1.12-14.36)$ & $16.88(1.12-34.91)$ & $1.12(1.12-1.87)$ & $1.12(1.12-14.94)$ \\
\hline IL-4 & $(\mathrm{pg} / \mathrm{ml})$ & $5.56(2.53-8.25)$ & $7.58(5.21-10.62)$ & $4.32(0.81-5.56)$ & $4.46(1.72-6.87)$ \\
\hline IL-5 & $(\mathrm{pg} / \mathrm{ml})$ & $17.48(13.25-29.07)$ & $23.22(15.11-36.60)$ & $16.40(5.32-25.88)$ & $15.30(3.02-34.37)$ \\
\hline IL-6 & $(\mathrm{pg} / \mathrm{ml})$ & $108.76(43.38-693.86)^{*}$ & $372.14(256.94-8,914.32)$ & $63.94(25.22-279.45)$ & $148.04(36.39-476.18)$ \\
\hline IL-7 & $(\mathrm{pg} / \mathrm{ml})$ & $7.12(3.49-22.74)$ & $10.14(5.47-25.29)$ & $10.14(2.56-17.51)$ & $7.04(2.38-26.49)$ \\
\hline IL-8 & $(\mathrm{pg} / \mathrm{ml})$ & $70.06(35.18-128.29)^{*}$ & $181.50(71.64-309.90)$ & $47.10(35.52-60.96)$ & $54.66(45.07-79.99)$ \\
\hline IL-9 & $(\mathrm{pg} / \mathrm{ml})$ & $10.58(5.11-21.22)$ & $24.50(9.28-40.76)$ & $10.76(3.67-14.46)$ & $21.60(4.84-50.33)$ \\
\hline IL-10 & $(\mathrm{pg} / \mathrm{ml})$ & $10.76(3.12-60.99)$ & $44.94(15.64-90.29)$ & $11.76(2.70-19.45)$ & $22.58(2.15-40.24)$ \\
\hline IL-12 & $(\mathrm{pg} / \mathrm{ml})$ & $12.90(5.59-46.92)$ & $24.70(17.40-45.64)$ & $14.40(3.67-34.50)$ & $16.82(4.85-53.85)$ \\
\hline IL-13 & $(\mathrm{pg} / \mathrm{ml})$ & $4.58(0.49-10.39)$ & $7.48(2.32-13.69)$ & $2.90(0.49-11.07)$ & $5.34(0.49-11.41)$ \\
\hline IL-15 & $(\mathrm{pg} / \mathrm{ml})$ & $2.18(1.36-42.09)^{*}$ & $30.52(11.05-69.96)$ & $2.20(1.36-6.54)$ & $14.92(1.36-36.92)$ \\
\hline IL-17 & $(\mathrm{pg} / \mathrm{ml})$ & $21.98(1.76-59.59)^{*}$ & $61.36(33.91-95.71)$ & $20.96(2.29-44.40)$ & $16.22(5.30-56.03)$ \\
\hline IFN- $\gamma$ & $(\mathrm{pg} / \mathrm{ml})$ & $141.98(52.02-236.75)$ & $235.00(132.64-367.44)$ & $106.74(11.40-175.60)$ & $111.46(31.02-246.25)$ \\
\hline TNF- $\alpha$ & $(\mathrm{pg} / \mathrm{ml})$ & $67.24(21.35-127.49)$ & $130.36(66.29-258.62)$ & $40.10(10.36-69.18)$ & $47.90(28.27-121.97)$ \\
\hline CRP & $(\mathrm{mg} / \mathrm{l})$ & $182.75(152.39-309.13)$ & $225.20(170.16-279.81)$ & $194.59(122.48-259.60)$ & $211.55(143.30-266.25)$ \\
\hline PCT & $(\mathrm{ng} / \mathrm{ml})$ & $2.64(0.63-4.19)$ & $3.14(1.22-5.84)$ & $1.26(0.50-2.63)$ & $1.86(0.50-4.55)$ \\
\hline LBP & $(\mu \mathrm{g} / \mathrm{ml})$ & $111.70(71.10-178.66)$ & $117.53(77.75-175.31)$ & $94.64(67.16-178.19)$ & $98.13(59.89-109.24)$ \\
\hline sCD14 & (ng/ml) & $\begin{array}{c}3,141.50(2,652.75- \\
3,596.50)\end{array}$ & $\begin{array}{c}3,256.50(2,741.00- \\
4,153.75)\end{array}$ & $\begin{array}{c}2,835.50(2,460.75- \\
3,211.00)\end{array}$ & $\begin{array}{c}2,812.00(2,103.25- \\
3,926.25)\end{array}$ \\
\hline sST2 & (ng/ml) & $311.56(137.45-501.29)$ & $460.20(291.00-616.22)$ & & \\
\hline Gas6 & (ng/ml) & $49.82(30.53-56.13)$ & $41.37(37.88-51.81)$ & $39.73(34.45-53.00)$ & 37.83 (30.14-55.57) \\
\hline \multicolumn{6}{|l|}{ Chemokines } \\
\hline MCP-1 & $(\mathrm{pg} / \mathrm{ml})$ & 77.84 (18.58-196.61) & $217.92(58.49-452.11)$ & $30.30(20.34-65.31)$ & $98.76(43.46-169.94)$ \\
\hline MIP- $1 \alpha$ & $(\mathrm{pg} / \mathrm{ml})$ & $7.40(3.60-13.36)$ & $9.76(7.45-12.92)$ & $5.72(0.06-8.84)$ & $6.44(1.34-10.68)$ \\
\hline MIP- $1 \beta$ & $(\mathrm{pg} / \mathrm{ml})$ & $113.96(86.25-136.21)$ & $140.10(99.45-250.56)$ & $87.68(66.20-118.70)$ & $87.80(69.61-206.18)$ \\
\hline RANTES & $(\mathrm{pg} / \mathrm{ml})$ & $1,761.46(358.78-2,779.92)$ & $\begin{array}{c}2,034.30(1,120.56- \\
4,104.55)\end{array}$ & $928.68(436.46-2,185.56)$ & $1,158.44(408.50-3,027.76)$ \\
\hline Eotaxin & $(\mathrm{pg} / \mathrm{ml})$ & $70.56(49.43-105.12)$ & $101.08(76.99-190.60)$ & $50.36(45.00-69.06)$ & $68.12(36.38-97.11)$ \\
\hline IP-10 & $(\mathrm{pg} / \mathrm{ml})$ & $1,256.80(863.08-2,267.60)$ & $1,572.08(698.69-3,027.45)$ & $1,230.46(602.92-2,062.71)$ & $853.12(530.21-2,442.66)$ \\
\hline \multicolumn{6}{|c|}{ Growth factors } \\
\hline G-CSF & $(\mathrm{pg} / \mathrm{ml})$ & $96.38(37.36-441.77)$ & $185.96(150.13-645.11)$ & $94.88(72.43-136.79)$ & $109.36(75.29-137.63)$ \\
\hline GM-CSF & $(\mathrm{pg} / \mathrm{ml})$ & $16.54(0.78-95.23)^{*}$ & $83.54(31.07-159.81)$ & $8.32(0.78-27.19)$ & $28.84(4.77-74.65)$ \\
\hline FGF & $(\mathrm{pg} / \mathrm{ml})$ & $61.88(21.93-107.02)$ & $93.12(66.33-119.76)$ & $49.48(5.12-82.51)$ & $51.00(4.09-95.82)$ \\
\hline PDGF & $(\mathrm{pg} / \mathrm{ml})$ & $91.70(45.13-187.68)^{*}$ & $152.26(83.73-266.76)$ & $59.62(29.91-98.59)$ & $63.66(15.67-146.77)$ \\
\hline VEGF & $(\mathrm{pg} / \mathrm{ml})$ & $9.84(1.80-51.50)^{*}$ & $44.02(18.84-61.46)$ & $7.48(1.80-22.88)$ & $20.36(4.92-36.96)$ \\
\hline \multicolumn{6}{|c|}{$\begin{array}{l}\text { Endothelial activation } \\
\text { markers }\end{array}$} \\
\hline ESM-1 & $(\mathrm{ng} / \mathrm{ml})$ & $4.76(3.75-7.90)$ & $7.24(4.11-21.60)$ & $5.86(2.81-12.89)$ & $16.39(4.69-44.79)$ \\
\hline Ang-1 & (ng/ml) & $0.56(0.29-1.02)$ & $0.73(0.50-1.31)$ & $0.36(0.14-0.77)$ & $0.62(0.14-1.26)$ \\
\hline Ang-2 & (ng/ml) & $15.21(6.42-27.03)$ & $13.03(8.93-56.98)$ & $10.42(8.06-18.55)$ & $10.09(7.96-18.37)$ \\
\hline${ }_{1}$ Ang-2/Ang & & $27.98(10.92-45.96)$ & $19.10(8.47-128.80)$ & $37.85(9.75-133.65)$ & $37.87(7.01-110.56)$ \\
\hline \multicolumn{6}{|c|}{ Damage-associated molecular patterns } \\
\hline ecDNA & $(\mathrm{ng} / \mathrm{ml})$ & $441.78(244.90-690.28)^{\mathrm{a}}$ & $657.27(397.96-1,542.62)$ & & \\
\hline
\end{tabular}


TABLE 5: Continued.

\begin{tabular}{|c|c|c|c|c|c|}
\hline \multirow{2}{*}{ Parameter } & & \multicolumn{2}{|c|}{$0 \mathrm{~h}$} & \multicolumn{2}{|c|}{$48 \mathrm{~h}$} \\
\hline & & $\operatorname{EMiC} 2(n=14)$ & AV1000S $(n=16)$ & $\operatorname{EMiC} 2(n=12)$ & AV1000S $(n=10)$ \\
\hline Histones & $(\mathrm{mg} / \mathrm{ml})$ & $0.60(0.46-22.29)^{\mathrm{a}}$ & $7.47(0.40-79.90)$ & & \\
\hline HMGB-1 & $(\mathrm{ng} / \mathrm{ml})$ & $2.99(2.55-6.63)^{\mathrm{a}}$ & $4.53(2.89-12.53)^{\mathrm{b}}$ & $2.99(2.50-4.56)^{\mathrm{b}, *}$ & $5.13(3.26-9.16)^{\mathrm{c}}$ \\
\hline \multicolumn{6}{|c|}{ Coagulation-related parameters } \\
\hline $\mathrm{TF}$ & $(\mathrm{pg} / \mathrm{ml})$ & $71.12(42.24-108.66)$ & $65.90(50.96-79.93)$ & & \\
\hline TF activity & $(\mathrm{pM})$ & $46.73(23.69-66.11)$ & $33.10(24.63-45.34)$ & & \\
\hline \multicolumn{6}{|l|}{ Others } \\
\hline Cystatin C & $(\mu \mathrm{g} / \mathrm{ml})$ & $3.26(2.60-4.00)^{*}$ & $3.91(3.61-4.20)$ & $2.68(2.52-3.21)^{*}$ & $3.46(3.03-3.86)$ \\
\hline Albumin & $(\mathrm{g} / \mathrm{dl})$ & $3.42(2.50-3.86)$ & $3.35(2.89-3.77)$ & $3.55(3.11-3.88)$ & $3.13(2.69-3.34)$ \\
\hline
\end{tabular}

Data are represented as median $\left(25^{\text {th }}-75^{\text {th }}\right.$ quartile). ${ }^{\mathrm{a}} n=13 ;{ }^{\mathrm{b}} n=14 ;{ }^{\mathrm{c}} n=8$. Differences in inflammatory mediator concentrations between filter groups at baseline and after $48 \mathrm{~h}$ were analyzed by the nonparametric Mann-Whitney test $\left({ }^{*} p<0.05\right)$.
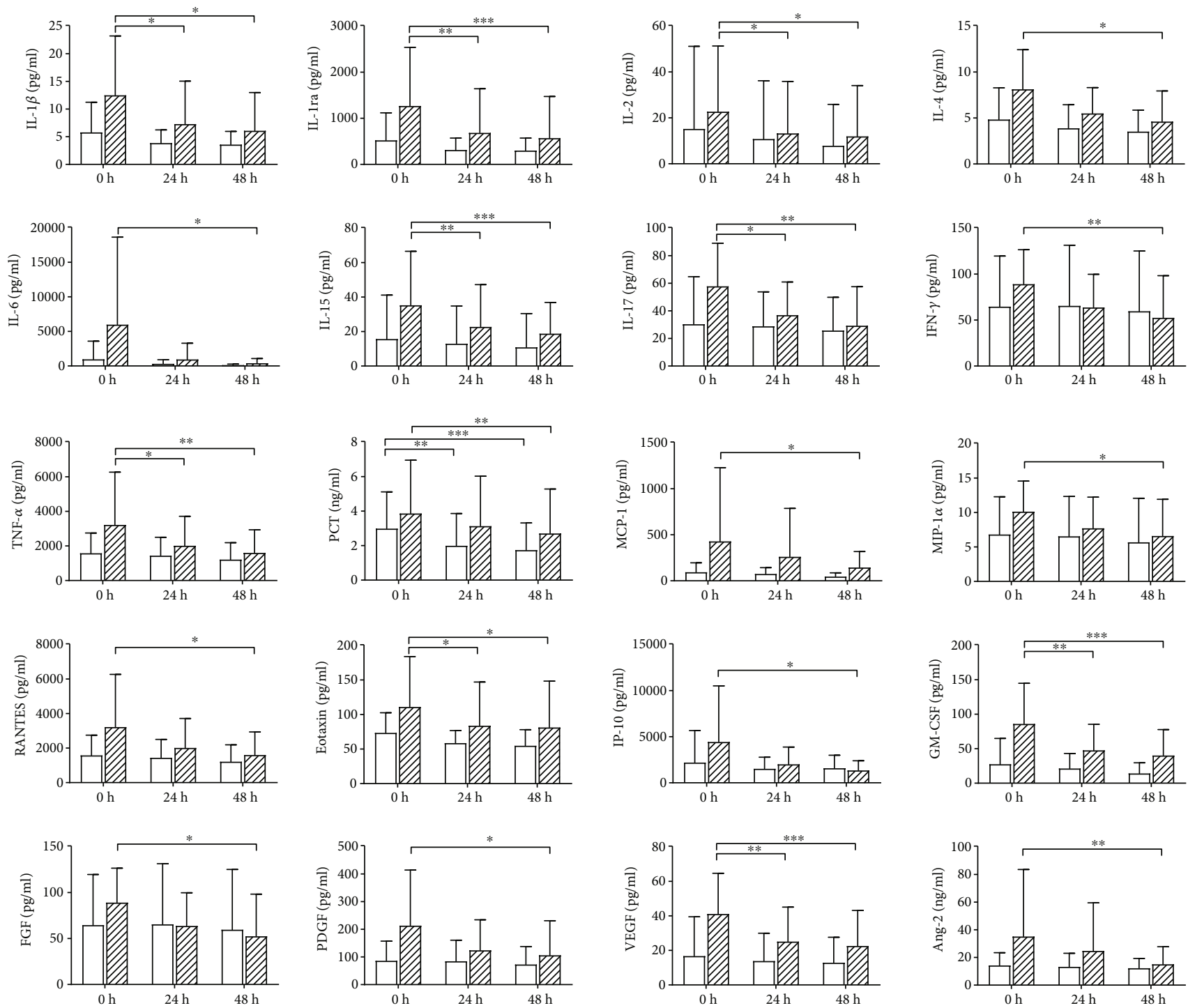

FIGURE 4: Effect of EMiC2 and AV1000S on inflammatory mediator concentrations over time (mean \pm standard deviation, repeated measures two-way ANOVA using Bonferroni's multiple comparison test; $n=12$ for EMiC2 (white bars), $n=10$ for AV1000S (hatched bars); ${ }^{*} p<0.05$, ${ }^{* *} p<0.01$, and $\left.{ }^{* * *} p<0.001\right)$. 
(Seraph 100 Microbind Affinity Blood Filter, ExThera Medical, Martinez, CA).

Finally, the findings of this study, specifically the wide concentration ranges of mediators in individual patients as well as the lack of consistency between clinical scores and biomarker levels, emphasize the current challenge of identifying distinct clinical phenotypes and of trial design and interpretation in sepsis patients [63].

\section{Data Availability}

All authors confirm that all relevant data are included in the article. Additional statistical data are available from the corresponding author upon request. Data supporting the findings of this study are provided as supplementary information accompanying this paper.

\section{Conflicts of Interest}

The authors have no conflict of interest to declare.

\section{Authors' Contributions}

TE performed the sample and data analysis and data interpretation and wrote the manuscript together with VW. TE, LL, and FK carried out the statistical analysis. IL, LL, CT, $\mathrm{BF}$, and RW performed the biochemical analysis. $\mathrm{CH}$ and VW designed and supervised the clinical study. GV, GM, and $\mathrm{CH}$ were involved in the inclusion process of study participants and treated the patients at the intensive care unit. VW conceived and coordinated the study, contributed to data interpretation, and wrote the manuscript together with TE. All authors approved the manuscript for submission.

\section{Acknowledgments}

The authors are indebted to the nurses and technicians at the intensive care unit and the central laboratory of the University Clinic St. Pölten for their support during the entire study. This work was funded by the Christian Doppler Society (Christian Doppler Laboratory for Innovative Therapy Approaches in Sepsis).

\section{Supplementary Materials}

Supplementary Table 1: Clinical characteristics of survivors and nonsurvivors at baseline. Supplementary Table 2: Biomarker profiles in survivors and nonsurvivors at baseline. (Supplementary Materials)

\section{References}

[1] M. Singer, C. S. Deutschman, C. W. Seymour et al., "The Third International Consensus Definitions for Sepsis and Septic Shock (Sepsis-3)," Journal of the American Medical Association, vol. 315, no. 8, pp. 801-810, 2016.

[2] K. Reinhart, R. Daniels, N. Kissoon, F. R. Machado, R. D. Schachter, and S. Finfer, "Recognizing sepsis as a global health priority - a WHO resolution," The New England Journal of Medicine, vol. 377, no. 5, pp. 414-417, 2017.
[3] R. Ding, Y. Meng, and X. Ma, "The central role of the inflammatory response in understanding the heterogeneity of Sepsis3," BioMed research international, vol. 2018, Article ID 5086516, 10 pages, 2018.

[4] A. Leligdowicz and M. A. Matthay, "Heterogeneity in sepsis: new biological evidence with clinical applications," Critical care., vol. 23, no. 1, p. 80, 2019.

[5] J. C. Marshall, "Why have clinical trials in sepsis failed?" Trends in molecular medicine., vol. 20, no. 4, pp. 195-203, 2014.

[6] J. Cohen and J. Carlet, "INTERSEPT: an international, multicenter, placebo-controlled trial of monoclonal antibody to human tumor necrosis factor-alpha in patients with sepsis. International Sepsis Trial Study Group," Critical care medicine., vol. 24, no. 9, pp. 1431-1440, 1996.

[7] S. M. Opal, C. J. Fisher, J.-F. A. Dhainaut et al., "Confirmatory interleukin-1 receptor antagonist trial in severe sepsis: a phase III, randomized, double-blind, placebo-controlled, multicenter trial. The Interleukin-1 Receptor Antagonist Sepsis Investigator Group," Critical care medicine, vol. 25, no. 7, pp. 11151124, 1997.

[8] D. M. Payen, The ABDOMIX Group, J. Guilhot et al., "Early use of polymyxin B hemoperfusion in patients with septic shock due to peritonitis: a multicenter randomized control trial," Intensive Care Medicine, vol. 41, no. 6, pp. 975-984, 2015.

[9] B. Venkatesh, S. Finfer, J. Cohen et al., "Hydrocortisone compared with placebo in patients with septic shock satisfying the Sepsis-3 diagnostic criteria and APROCCHSS study inclusion criteria," Anesthesiology, vol. 131, no. 6, pp. 1292-1300, 2019.

[10] B. Shakoory, J. A. Carcillo, W. W. Chatham et al., "Interleukin1 receptor blockade is associated with reduced mortality in sepsis patients with features of macrophage activation syndrome: reanalysis of a prior phase III trial," Critical care medicine., vol. 44, no. 2, pp. 275-281, 2016.

[11] K. Reinhart, C. Wiegand-Lohnert, F. Grimminger et al., "Assessment of the safety and efficacy of the monoclonal anti-tumor necrosis factor antibody-fragment, MAK 195F, in patients with sepsis and septic shock: a multicenter, randomized, placebo-controlled, dose-ranging study," Critical care medicine., vol. 24, no. 5, pp. 733-742, 1996.

[12] W. Schulte, J. Bernhagen, and R. Bucala, "Cytokines in Sepsis: Potent Immunoregulators and Potential Therapeutic Targets-An Updated View," Mediators of Inflammation, vol. 2013, Article ID 165974, 16 pages, 2013.

[13] O. Takeuchi and S. Akira, "Pattern recognition receptors and inflammation," Cell, vol. 140, no. 6, pp. 805-820, 2010.

[14] W. J. Wiersinga, S. J. Leopold, D. R. Cranendonk, and T. van der Poll, "Host innate immune responses to sepsis," Virulence, vol. 5, no. 1, pp. 36-44, 2013.

[15] N. L. Denning, M. Aziz, S. D. Gurien, and P. Wang, "DAMPs and NETs in sepsis," Frontiers in immunology, vol. 10, 2019.

[16] T. Iba and J. H. Levy, "Inflammation and thrombosis: roles of neutrophils, platelets and endothelial cells and their interactions in thrombus formation during sepsis," Journal of thrombosis and haemostasis: JTH., vol. 16, no. 2, pp. 231-241, 2018.

[17] C. Ince, P. R. Mayeux, T. Nguyen et al., "The endothelium in sepsis," Shock, vol. 45, no. 3, pp. 259-270, 2016.

[18] R. S. Hotchkiss, G. Monneret, and D. Payen, "Sepsis-induced immunosuppression: from cellular dysfunctions to immunotherapy," Nature Reviews. Immunology, vol. 13, no. 12, pp. 862-874, 2013. 
[19] J. S. Boomer, J. M. Green, and R. S. Hotchkiss, “The changing immune system in sepsis: is individualized immunomodulatory therapy the answer?," Virulence, vol. 5, no. 1, pp. 45-56, 2013.

[20] G. Ankawi, M. Neri, J. Zhang, A. Breglia, Z. Ricci, and C. Ronco, "Extracorporeal techniques for the treatment of critically ill patients with sepsis beyond conventional blood purification therapy: the promises and the pitfalls," Critical care., vol. 22, no. 1, p. 262, 2018.

[21] T. Eichhorn, J. Hartmann, S. Harm et al., "Clearance of selected plasma cytokines with continuous veno-venous hemodialysis using Ultraflux EMiC2 versus Ultraflux AV1000S," Blood Purification, vol. 44, no. 4, pp. 260-266, 2017.

[22] T. Eichhorn, S. Rauscher, C. Hammer, M. Groger, M. B. Fischer, and V. Weber, "Polystyrene-divinylbenzene-based adsorbents reduce endothelial activation and monocyte adhesion under septic conditions in a pore size-dependent manner," Inflammation, vol. 39, no. 5, pp. 1737-1746, 2016.

[23] W. Van Biesen, R. Vanholder, and N. Lameire, "Defining acute renal failure: RIFLE and beyond," Clinical journal of the American Society of Nephrology : CJASN., vol. 1, no. 6, pp. 13141319, 2006.

[24] R. C. Bone, R. A. Balk, F. B. Cerra et al., "Definitions for sepsis and organ failure and guidelines for the use of innovative therapies in sepsis. The ACCP/SCCM Consensus Conference Committee. American College of Chest Physicians/Society of Critical Care Medicine," Chest, vol. 101, no. 6, pp. 1644-1655, 1992.

[25] P. Lassalle, S. Molet, A. Janin et al., "ESM-1 Is a Novel Human Endothelial Cell-specific Molecule Expressed in Lung and Regulated by Cytokines*," The Journal of biological chemistry., vol. 271, no. 34, pp. 20458-20464, 1996.

[26] A. Palud, E. Parmentier-Decrucq, J. Pastre, N. D. F. Caires, P. Lassalle, and D. Mathieu, "Evaluation of endothelial biomarkers as predictors of organ failures in septic shock patients," Cytokine, vol. 73, no. 2, pp. 213-218, 2015.

[27] D. Pauly, S. Hamed, M. Behnes et al., "Endothelial cell-specific molecule-1/endocan: diagnostic and prognostic value in patients suffering from severe sepsis and septic shock," Journal of critical care., vol. 31, no. 1, pp. 68-75, 2016.

[28] T. Ziegler, J. Horstkotte, C. Schwab et al., "Angiopoietin 2 mediates microvascular and hemodynamic alterations in sepsis," The Journal of clinical investigation., vol. 123, no. 8, pp. 3436-3445, 2013.

[29] C. H. Seol, S. H. Yong, J. H. Shin et al., "The ratio of plasma angiopoietin-2 to angiopoietin-1 as a prognostic biomarker in patients with sepsis," Cytokine, vol. 129, p. 155029, 2020.

[30] Y. Fang, C. Li, R. Shao, H. Yu, Q. Zhang, and L. Zhao, "Prognostic significance of the angiopoietin-2/angiopoietin-1 and angiopoietin-1/Tie-2 ratios for early sepsis in an emergency department," Critical care, vol. 19, no. 1, 2015.

[31] E. Christaki and E. J. Giamarellos-Bourboulis, "The beginning of personalized medicine in sepsis: small steps to a bright future," Clinical genetics., vol. 86, no. 1, pp. 56-61, 2014.

[32] P. Schuetz, "'Personalized" sepsis care with the help of specific biomarker levels on admission and during follow up: are we there yet?," Clinical chemistry and laboratory medicine., vol. 53, no. 4, pp. 515-517, 2015.

[33] V. Lvovschi, L. Arnaud, C. Parizot et al., "Cytokine profiles in sepsis have limited relevance for stratifying patients in the emergency department: a prospective observational study," PLoS One, vol. 6, no. 12, article e28870, 2011.
[34] A. Oberholzer, S. M. Souza, S. K. Tschoeke et al., "Plasma cytokine measurements augment prognostic scores as indicators of outcome in patients with severe sepsis," Shock, vol. 23, no. 6, pp. 488-493, 2005.

[35] L. F. Gentile, A. G. Cuenca, E. L. Vanzant et al., "Is there value in plasma cytokine measurements in patients with severe trauma and sepsis?," Methods, vol. 61, no. 1, pp. 3-9, 2013.

[36] F. A. Bozza, J. I. Salluh, A. M. Japiassu et al., "Cytokine profiles as markers of disease severity in sepsis: a multiplex analysis," Critical care., vol. 11, no. 2, p. R49, 2007.

[37] D. Andaluz-Ojeda, F. Bobillo, V. Iglesias et al., "A combined score of pro- and anti-inflammatory interleukins improves mortality prediction in severe sepsis," Cytokine, vol. 57, no. 3, pp. 332-336, 2012.

[38] A. Walborn, D. Hoppensteadt, D. Syed, M. Mosier, and J. Fareed, "Biomarker profile of sepsis-associated coagulopathy using biochip assay for inflammatory cytokines," Clinical and Applied Thrombosis/Hemostasis, vol. 24, no. 4, pp. 625-632, 2017.

[39] E. Tamayo, A. Fernández, R. Almansa et al., "Pro- and antiinflammatory responses are regulated simultaneously from the first moments of septic shock," European cytokine network., vol. 22, no. 2, pp. 82-87, 2011.

[40] R. L. Kitchens and P. A. Thompson, "Modulatory effects of sCD14 and LBP on LPS-host cell interactions," Journal of endotoxin research., vol. 11, no. 4, pp. 225-229, 2005.

[41] N. Lamping, R. Dettmer, N. W. Schröder et al., "LPS-binding protein protects mice from septic shock caused by LPS or gram-negative bacteria," The Journal of clinical investigation, vol. 101, no. 10, pp. 2065-2071, 1998.

[42] J. Zweigner, H. J. Gramm, O. C. Singer, K. Wegscheider, and R. R. Schumann, "High concentrations of lipopolysaccharide-binding protein in serum of patients with severe sepsis or septic shock inhibit the lipopolysaccharide response in human monocytes," Blood, vol. 98, no. 13, pp. 3800-3808, 2001.

[43] F. Liu, L. Li, M. Xu et al., "Prognostic value of interleukin-6, Creactive protein, and procalcitonin in patients with COVID19," Journal of clinical virology: the official publication of the Pan American Society for Clinical Virology., vol. 127, p. 104370, 2020.

[44] H. Wang, M. F. Ward, and A. E. Sama, "Targeting HMGB1 in the treatment of sepsis," Expert opinion on therapeutic targets., vol. 18 , no. 3, pp. 257-268, 2014.

[45] J. M. Tadie, H. B. Bae, S. Jiang et al., "HMGB1 promotes neutrophil extracellular trap formation through interactions with Toll-like receptor 4," American journal of physiology Lung cellular and molecular physiology., vol. 304, no. 5, pp. L342-L349, 2013.

[46] S. Yang, H. Qi, K. Kan et al., "Neutrophil extracellular traps promote hypercoagulability in patients with sepsis," Shock, vol. 47, no. 2, pp. 132-139, 2017.

[47] P. G. Czaikoski, J. M. S. C. Mota, D. C. Nascimento et al., "Neutrophil extracellular traps induce organ damage during experimental and clinical sepsis," PLoS One, vol. 11, no. 2, article e0148142, 2016.

[48] C. Kawai, H. Kotani, M. Miyao et al., "Circulating extracellular histones are clinically relevant mediators of multiple organ injury," The American journal of pathology., vol. 186, no. 4, pp. 829-843, 2016.

[49] F. Semeraro, C. T. Ammollo, J. H. Morrissey et al., "Extracellular histones promote thrombin generation through platelet- 
dependent mechanisms: involvement of platelet TLR2 and TLR4," Blood, vol. 118, no. 7, pp. 1952-1961, 2011.

[50] J. Xu, X. Zhang, R. Pelayo et al., "Extracellular histones are major mediators of death in sepsis," Nature Medicine, vol. 15, no. 11, pp. 1318-1321, 2009.

[51] T. A. Fuchs, A. A. Bhandari, and D. D. Wagner, "Histones induce rapid and profound thrombocytopenia in mice," Blood, vol. 118, no. 13, pp. 3708-3714, 2011.

[52] P. I. Johansson, N. A. Windelov, L. S. Rasmussen, A. M. Sorensen, and S. R. Ostrowski, "Blood levels of histone-complexed DNA fragments are associated with coagulopathy, inflammation and endothelial damage early after trauma," Journal of emergencies, trauma, and shock., vol. 6, no. 3, pp. 171-175, 2013.

[53] Z. Xu, Y. Huang, P. Mao, J. Zhang, and Y. Li, "Sepsis and ARDS: the dark side of histones," Mediators of Inflammation, vol. 2015, Article ID 205054, 9 pages, 2015.

[54] X. Yang, L. Li, J. Liu, B. Lv, and F. Chen, "Extracellular histones induce tissue factor expression in vascular endothelial cells via TLR and activation of NF- $\kappa$ B and AP-1," Thrombosis research., vol. 137, pp. 211-218, 2016.

[55] J. E. Kim, H. J. Yoo, J. Y. Gu, and H. K. Kim, "Histones induce the procoagulant phenotype of endothelial cells through tissue factor up-regulation and thrombomodulin down-regulation," PLoS One, vol. 11, no. 6, article e0156763, 2016.

[56] K. C. A. A. Wildhagen, M. A. Wiewel, M. J. Schultz et al., "Extracellular histone $\mathrm{H} 3$ levels are inversely correlated with antithrombin levels and platelet counts and are associated with mortality in sepsis patients," Thrombosis research, vol. 136, no. 3, pp. 542-547, 2015.

[57] M. L. Ekaney, G. P. Otto, M. Sossdorf et al., "Impact of plasma histones in human sepsis and their contribution to cellular injury and inflammation," Critical care., vol. 18, no. 5, p. 543, 2014.

[58] Y. Yokoyama, T. Ito, T. Yasuda et al., "Circulating histone H3 levels in septic patients are associated with coagulopathy, multiple organ failure, and death: a single-center observational study," Thrombosis journal, vol. 17, no. 1, 2019.

[59] A. Kali and K. S. Shetty, "Endocan: a novel circulating proteoglycan," Indian journal of pharmacology, vol. 46, no. 6, pp. 579-583, 2014.

[60] G. I. Zonda, R. Zonda, A. T. Cernomaz, L. Paduraru, A. L. Avasiloaiei, and B. D. Grigoriu, "Endocan - a potential diagnostic marker for early onset sepsis in neonates," Journal of infection in developing countries., vol. 13, no. 4, pp. 311-317, 2019.

[61] D. Béchard, A. Scherpereel, H. Hammad et al., "Human endothelial-cell specific molecule-1 binds directly to the integrin CD11a/CD18 (LFA-1) and blocks binding to intercellular adhesion molecule-1," Journal of Immunology, vol. 167, no. 6, pp. 3099-3106, 2001.

[62] C. Mikacenic, W. O. Hahn, B. L. Price et al., "Biomarkers of endothelial activation are associated with poor outcome in critical illness," PLoS One, vol. 10, no. 10, article e0141251, 2015.

[63] N. Beckmann, C. E. Salyer, P. A. Crisologo, V. Nomellini, and C. C. Caldwell, "Staging and personalized intervention for infection and sepsis," Surgical infections., vol. 21, no. 9, pp. 732-744, 2020. 